\title{
Iliac Artery
}

National Cancer Institute

\section{Source}

National Cancer Institute. Iliac Artery. NCI Thesaurus. Code C12733.

A branch of the abdominal aorta that supplies blood to the lower trunk and the legs. 